\title{
A UNIVERSIDADE E A SOCIEDADE NO DIVÃ DO PSICANALISTA: DOS DESAFIOS QUE SE IMPÕEM À UNIVERSIDADE, ENQUANTO FILHA BASTARDA DO ESTADO
}

Recebido em: 07-07-2020-Aceito em: 20-07-2020

DOI: http://dx.doi.org/10.5902/2526629235592

\section{INTRODUÇÃO}

A universidade é uma instituição milenar, isto é, um agente de construção e de sustentabilidade dos processos civilizatórios da humanidade. É presença secular e capilar mundial. No Brasil, é centenária e constitutiva de um importante sistema federal de instituições presentes em todo o território nacional. Nesta longa trajetória de construção e de reconstrução, a universidade tem marcado sua presença resiliente com profundidade e viva atuação, disponibilizando à humanidade instrumentos científicos, educacionais, tecnológicos e profissionais, geradores de avanços e de desenvolvimento das sociedades, atendendo suas demandas e necessidades em diferentes processos.

A presença e os feitos da universidade, ao longo do último século, também têm Ihe permitido angariar respeitabilidade, permanência e valor universal. Mas, paradoxalmente, esta tem sofrido críticas provenientes de governantes, políticos e representantes de diferentes setores da sociedade. Opiniões essas que têm origem em setores da sociedade que menosprezam o conhecimento, a ciência, a tecnologia, a cultura e os valores sociais. E isso, em tempos estranhos e "bicudos", como os que estamos vivendo, se expressa de maneira mais frequente e contundente através de políticas e discursos oficiais que operam sem nenhum embasamento científico, num quase exercício de espontaneísmo canhestro daqueles que, por exemplo, hoje exercem as políticas de saúde e combate à pandemia em nosso país.

Porém, e "apesar de", é a universidade a quem a sociedade recorre em busca de respostas as suas demandas, as suas urgências, e, também, é nesta que repousa a sua confiança. Podemos dizer que é a ela - universidade - que a sociedade "pede socorro", onde encontra a liderança necessária e de quem sempre recebe a solidariedade. Com isto, tem-se que nesta inimaginável e inesperada 
crise que chega e se instala, pelo lado da saúde, a qual tem tido impactos profundos em toda a vida socioeconômica, político-institucional, identitária e cultural, é na universidade, mais uma vez, que a sociedade tem buscado um "porto seguro". Instituição essa que é sempre visualizada como a principal referência, no que tange a busca por conhecimento, solidariedade e valores que possam orientar todos os atores e agentes sociais. A universidade surge nessas ocasiões como locus de liderança, de resistência e de aglutinação. É assim lembrada!!... E em alguns importantes momentos!

Não é pouco o que a universidade tem a oferecer e o que ao longo do tempo produziu. Não é pequena a sua potencialidade para, hoje, ser disponibilizada, construir propostas e ativos para a solução das questões decorrentes da pandemia de COVID-19. Para tanto, dois são os movimentos a serem perseguidos. $O$ primeiro refere-se ao reconhecimento de que as universidades têm incalculável acervo de conhecimentos, parâmetros e respostas científicas e tecnológicas capazes de fundamentar descobertas e avanços disponibilizados à humanidade no sentido de encontrar os meios de combate à crise sanitária presente e de prever o enfrentamento dos desafios, incertos e inesperados, que se põem aos novos tempos, advindos da crise fulcral que afeta as diferentes áreas e setores da vida. Conhecimento esse materializado em respiradores de baixo custo desenvolvidos em nossas universidades, bem como no estágio bastante avançado em que já estão algumas vacinas experimentais desenvolvidas, inclusive, em centros de pesquisa ligados a diversas universidades brasileiras, e/ou em regime de cooperação internacional.

O segundo momento consiste em identificar os desafios de caráter e natureza desconhecida que esses novos tempos apresentam. De modo especial, aqueles que afetam a incerteza, a extensão e a surpresa das formas como a nova ordem mundial - em estabelecimento - atinge frontalmente as instituições universitárias, a sociedade e a vida humana em geral, e que, até o momento, por exemplo, tem demonstrado exigir que se conforme com um novo modo de se relacionar, de trabalhar e de consumir.

\section{DA ANAMNESE}

O progresso resultante do trabalho, às vezes, moroso e quase "artesanal", de pesquisadores e cientistas ao longo do tempo, além de possuir um extraordinário acervo e uma riqueza patrimonial, chega até parecer "mágico" diante das aventuras vivenciadas pelos artífices da ficção científica que assume ares de possível 
realidade a instigar a humanidade. É desta forma que James T. Kirk expõe as suas peripécias, que outra coisa não são do que "fantasias" (realidade fantástica!?) a nos provocar a imaginação. E, neste sentido, lembro aqui a conhecida frase de abertura da série de TV Jornada nas Estrelas em que ele diz:

O espaço...

A fronteira final...

Estas são as viagens da nave estelar Enterprise, em sua missão de cinco anos para explorar novos mundos, pesquisar novas vidas, novas civilizações...

Audaciosamente indo, onde nenhum homem jamais esteve!

Daí porque o fazer acadêmico - construção do conhecimento - aparentemente mais lento, mas certamente mais fundamentado e testado, apresenta maior consistência e veracidade. Nesse sentido, as aventuras de Kirk ainda são uma ficção, longe de ser tornada realidade.

Para os que produzem conhecimento, promovem instrumentos técnicos, fabricam invenções e explicam a realidade, a sua concretude pari passu se realiza e apresenta resultados a serem utilizados e à serviço do conjunto da humanidade. Aí estão alguns objetos e instrumentos que eram tidos como impossíveis de serem concebidos até pouco tempo atrás $-30,40,50$ anos... -, mas que hoje são realidade e fazem parte de nosso cotidiano e seria difícil imaginar nossa vida sem eles, diga-se de passagem.

Exemplo disso é o fato de estarmos, muitas vezes, à distância conectados e vendo uns aos outros. Algo que era tido como impossível, no início dos anos 1980 , e que, no entanto, fora bastante comum nos filmes que buscavam explorar as distopias de um mundo possível para a humanidade. Quando imaginaríamos, no início daqueles anos, que poderíamos estar conectados das nossas casas por meio de um computador ou aparelho celular -conversando, vendo pessoas e interagindo com indivíduos que estão localizados a centenas e milhares de quilômetros de distância?

Se lembrarmos bem, no início daqueles anos, para se usar o computador e processar algo - como uma simples equação -, era preciso ir até o Centro de Processamento de Dados da Universidade e reservar um horário, bem como, antes disso, perder de cinco a seis horas perfurando cartões para se realizar o referido 
cálculo. Algo que, hoje, nosso celular faz em menos de três segundos.

Estes processos de avanços científicos e tecnológicos podem ser observados em diferentes setores do conhecimento. Assim, em uma breve digressão e a partir de algumas grandes áreas da ciência moderna - compartimentada e pensada no interior das instituições de pesquisa - é possível verificar que:

a. No âmbito das Ciências Humanas, nunca imaginaríamos ser possível reduzir os índices de pobreza e desigualdade social, garantindo às populações menos favorecidas a oportunidade de chegar até a Universidade - seja por meio de programas tais como o REUNI, junto às Universidades Públicas, e o PROUNI, junto às Universidades Privadas -; e/ou que a instituição de ensino superior pudesse se relacionar com a sociedade, via projetos de extensão com grande incidência social como, por exemplo, é caso do tão conhecido e paradigmático Projeto Rondon.

b. No âmbito das Ciências Sociais Aplicadas, nunca imaginaríamos que pequenas mudanças no modo de fazer a gestão de recursos humanos e não-humanos, no interior de diferentes empresas e instituições, como é o caso das universidades e das empresas em relação ao trabalho em Home Office, implicaria em mudanças estruturais e na necessidade de tanto as empresas quanto as universidades, e, também, os trabalhadores a elas ligados, reinventarem-se e aprenderem a comunicar-se e relacionar-se remotamente com seus alunos, fornecedores e clientes.

c. No âmbito da Linguística, Letras e Artes, nunca imaginaríamos que seria possível, em casa, produzir digitalmente textos - como este, escrito em um conhecido editor de textos, o Word - e imagens tridimensionais, por meio de alguns softwares para edição de imagens - o Photoshop e o ArqCad -, de modo que um livro, ou mesmo uma cidade inteira, seja capaz de caber no seu colo, na sua mão, ou ainda na tela de um celular - como esse que você tem no seu bolso, neste momento.

d. No âmbito das Ciências Agrárias, nunca imaginaríamos que seria possível monitorar a produção de grãos do espaço, por meio do uso de satélites, bem como identificar possíveis queimadas ou desmatamentos irregulares, por meio do uso de câmeras de alta resolução e/ou de leitura infravermelha realizada por satélites que orbitam o nosso planeta.

e. No âmbito das Ciências Biológicas, nunca imaginaríamos que um simples fungo se tornaria um dos mais poderosos antibióticos e salvaria a 
vida de centenas de milhares de pessoas, ao longo deste século, como é caso da penicilina, ou ainda, que seríamos capazes de manipular geneticamente espécies vegetais, bactérias e outras formas de vida para que estes produzam mais alimentos, para que fermentem o leite, transformando-o em iogurte, ou ainda, para que reduzam os índices de poluição das águas, por exemplo.

f. No âmbito das Ciências da Saúde, nunca imaginaríamos que um simples pedaço de RNA de um vírus seria capaz de nos imunizar contra ele, por meio de uma simples vacina e/ou de algumas gotinhas embaixo da língua, a ponto de conseguirmos erradicar de nosso país doenças que, durante muito tempo, eram tidas como fatais - como, por exemplo, a tuberculose, a poliomielite, a varíola, o sarampo e, mais recentemente, o ebola? E, nos dias atuais, a primeira vacina para a COVID-19, que no momento da escrita deste artigo já se encontra em testes clínicos em humanos, em diversos países.

g. No âmbito das Ciências da Terra, nunca imaginaríamos que poderíamos produzir energia elétrica limpa a partir de estações geotermais, das ondas do mar, ou mesmo do vento - como é o caso do parque eólico de Osório, no Rio Grande do Sul.

h. No âmbito das Ciências Exatas, nunca imaginaríamos que seríamos capazes de processar milhares de pentabites de informação em computadores instalados em nossos gabinetes na universidade ou mesmo na palma de nossa mão, por meio de um aparelho celular, em poucos segundos.

i. No âmbito das Engenharias, nunca imaginaríamos que seríamos capazes de produzir casas inteiras e/ou todo e qualquer tipo de peça de reposição para uma estação orbital - ou mesmo próteses corporais e implantes - pelo uso de impressoras 3D, ou ainda, que, num curto espaço de tempo, seríamos capazes de projetar e desenvolver respiradores de baixo custo como os que, hoje, estão chegando ao mercado em função da pandemia de COVID-19 e que foram desenvolvidos nos laboratórios de nossas universidades.

Sim, a filha bastarda do Estado, a universidade, apesar de ter sido deixada de lado durante muito tempo, seguiu seu caminho com suas próprias pernas, enfrentou os desafios que o mundo e a vida Ihe impuseram. E hoje, o Estado 
brasileiro, já senil, que não dá mais conta de cuidar de si nem de suas próprias atribuições, deixa de lado os bancos e os grandes interesses do capital - tidos até então como seus filhos pródigos - e vem até sua filha bastarda pedir alento e socorro para cuidar da sociedade.

\section{DO DIAGNÓSTICO}

Sim, a universidade é uma instituição secular e, desde muito tempo, tem dado suporte à sociedade e permitido que o homem avance rumo ao infinito - de modo que os últimos anos têm sido de muitos progressos científicos e tecnológicos. Este é um trabalho permanente, e hoje, em plena crise da saúde e de seus diferentes setores e alcances, as universidades têm um enorme repertório de estudos e pesquisas, feitos a cada dia e entregues à sociedade. Para tanto, basta averiguar o que foi apresentado por elas no I Congresso da ANDIFES (Associação Nacional de Dirigentes de Instituições Federais de Ensino Superior), realizado nos dias 17 e 18 do mês de junho'.

Contudo, eu gostaria de lembrar, junto ao que já foi dito, uma importante invenção, se não a maior delas, que é a escrita. Pois, esta nos permite documentar o passado, registrar o presente, prospectar o futuro, e, assim, avançar a partir do ponto em que os outros pararam e passar o nosso legado às futuras gerações. Pois ela, a escrita, é um elo de manutenção e ligação entre aquilo que é e o que foi produzido em diferentes tempos e lugares.

Portanto, é justamente neste último ponto que reside o grande desafio que se impõe à universidade, com vistas ao seu papel de preservar e promover a vida, qual seja: o de fomentar e de explorar o desenvolvimento de valores na sociedade. Valores que, há muito, os atuais modelos e atores do desenvolvimento econômico, social, cultural e político têm menosprezado, na medida em que o acesso, o uso e os benefícios obtidos se restringem a partes da humanidade, acentuando a exclusão de significativas parcelas da população do planeta. Valores esses construídos para todos, mas, de fato, utilizados por poucos. No entanto, são esses valores que nos permitem responder: como se produz a ciência? Para o que se faz ciência? E para quem essa ciência é dirigida?

Seu valor e importância são subtraídos na medida em que os princípios de igualdade, fraternidade, solidariedade e democracia são esquecidos. Tornam-se "letra morta" e, quando implantados, revelam, na realidade, sua ambiguidade, tão bem explicitada na expressão de Francisco de Oliveira: "as ideias fora de lugar e o lugar fora das ideias". Sentença essa que, desde muito tempo, tem servido 
ao Estado como forma de renegar àquela que ele tem como uma filha bastarda, a universidade, em favor de seus "irmãos pródigos" que apenas usurpam das famílias brasileiras a comida de sua mesa sob a égide de estar usando o dinheiro público - dinheiro público não existe, não se cria, ele sai da mesa do trabalhador e do contribuinte e, para que alguém possa contar com ele em seu orçamento, outro tem que ficar sem.

Dito de outra forma, e concluso esse diagnóstico, podemos dizer que as grandes e destruidoras crises pelas quais a humanidade atravessa, de quando em quando, que no tempo presente uma delas nos assola - a pandemia de COVID-2019 -, de um lado evidenciam a grandeza da ciência e, de outro, a sua pequenez e seu restrito valor de uso. Relação manifestada a partir do modo como o Estado, desde muito, tem se relacionado e tratado a universidade.

\section{DOS RESULTADOS ESPERADOS DA SEÇÃO}

São essas as constatações que, ao mesmo tempo em que apresentam um significado superlativo, revelam um esgarçamento e uma consequente e perplexa paralisia das universidades públicas que se veem sufocadas diante de pesados desafios que, sem dúvida, podem definir, de modo duradouro, o seu futuro, como salientou Roberto Leher em recente artigo e num provocativo debate organizado pela Universidade de Juiz de Fora, no congresso da ANDIFES, acima menciona$\mathrm{do}^{2}$. É por isso que, apesar do tom metafórico com o qual nos ocupamos neste breve ensaio, buscamos constelar os interesses e as relações que estão em jogo nesse momento de tão profunda crise social, econômica e política. Ou seja, neste ensaio, comparamos a relação macrossistêmica existente entre o Estado e a Sociedade - do Estado com a Universidade, os Bancos e os Interesses do Capital - com o plano microssistêmico da família.

Nesse contexto de pandemia, de quarentena, de isolamento social e de incapacidade de garantir condições mínimas de renda a grande parte da população brasileira - tanto por parte do Estado quanto de seus filhos pródigos -, a responsabilidade de dar uma resposta aos problemas com os quais o Estado não consegue lidar, hoje, está nos ombros daquela a quem este sempre teve como uma filha bastarda. É fato que estamos diante de um futuro incerto e que a universidade, enquanto instituição, também tem os seus dilemas. Contudo, estamos diante de um novo tempo, com demandas diferenciadas, pouco conhecidas, e com outros modos de fazer e de operacionalizar a vida acadêmica que são exigidos, mas que 
ainda necessitam ser pensados, construídos, planejados e gestionados, a partir de novos e provocadores parâmetros.

Em função disso, tem-se que, mais uma vez, estamos diante de um momento histórico no qual a universidade é instada a se transformar e a se reconstruir para desempenhar, com efetividade e legitimidade, o seu papel da filha que, mesmo execrada pelo pai, nunca deixa os seus e a sociedade a mercê do seu algoz, o Estado. E, assim, conseguir oferecer as respostas que dela são exigidas nesse momento.

Respostas essas que somente serão encontradas a partir de ações sustentadas e balizadas por um conjunto de valores consensuados em alguns grandes princípios, quais sejam: a) a excelência acadêmica, sem a exclusão de áreas, setores, pessoas e compromissos sociais, políticos e econômicos assumidos anteriormente; b) a inclusão social, tendo em vista a sua natureza institucional enquanto res publica, coisa de todos e para todos; c) as condições de trabalho qualificadas, inovadoras, próprias ao conteúdo intrínseco da instituição, enquanto produtora de bens públicos; e, também, d) o uso de novos instrumentos tecnológicos de comunicação, informática e produção digital.

\footnotetext{
${ }^{1}$ Disponível em: https://youtu.be/EPtzm-XzN3o.

${ }^{2}$ LEHER, Roberto. Universidades Públicas, aulas remotas e os desafios da ameaça neofascista no Brasil. Carta Maior, 02/06/2020. Disponível em:

https://www.cartamaior.com.br/?/Editoria/Educacao/Universidades-publicas-aulas-remotas-e-os-desafios-da-ameaca-neofascista-no-Brasil/54/47699. Acesso em: 29 jun. 2020.
} 